\title{
Decreased Maternal Serum 2-Methoxyestradiol Levels are Associated with the Development of Preeclampsia
}

\author{
Zhijun Shen ${ }^{\mathrm{a}}$ Yanming Wu ${ }^{\mathrm{b}}$ Xiao Chen ${ }^{\mathrm{b}}$ Xinwen Chang ${ }^{\mathrm{b}}$ Qian Zhou ${ }^{\mathrm{b}}$ Jian Zhou $^{\mathrm{c}}$ \\ Hao Ying ${ }^{c}$ Jing Zheng ${ }^{d}$ Tao Duan ${ }^{b, c}$ Kai Wang ${ }^{b}$
}

aDepartment of Laboratory Medicine, Shanghai First Maternity and Infant Hospital, Tongji University School of Medicine, Shanghai, ${ }^{b} C l i n i c a l$ and Translational Research Center, Shanghai First Maternity and Infant Hospital, Tongji University School of Medicine, Shanghai, 'Department of Obstetrics, Shanghai First Maternity and Infant Hospital, Tongji University School of Medicine, Shanghai, P.R. China; dDepartment of Ob/Gyn, University of Wisconsin, Madison, WI, USA

\section{Key Words}

2-ME • COMT • Preeclampsia • Trophoblast • Cell proliferation and migration

\begin{abstract}
Background: 2-methoxyestradiol (2-ME), a natural metabolite of $17 \beta$-estradiol, is synthesized by catechol-O-methyltransferase (COMT). The aim of this study was to explore the maternal 2-ME concentration and placental COMT expression in the different trimesters of normal pregnancy and preeclamptic pregnancies, as well as the effects of 2-ME on cell proliferation and migration of HTR-8/SVneo under normoxic $\left(20 \% \mathrm{O}_{2}\right)$ and hypoxic $\left(2.5 \% \mathrm{O}_{2}\right)$ conditions. Methods: 2-ME levels were examined by ELISA. COMT protein expression was analyzed by Western blot and immunohistochemistry. Cell proliferation and migration were measured by crystal violet assay and transwell system under either normoxia or hypoxia. Results: Maternal 2-ME concentration was elevated with the progression of pregnancy, in contrast, 2-ME was lower in women diagnosed with mild preeclampsia (mPE; $23 \%$ ) and severe preeclampsia (sPE; $32 \%$ ) as compared with normotensive full term pregnancies. Meanwhile, preterm controls had lower levels of 2-ME than full term controls. Soluble cytoplasmic COMT (S-COMT), but not membrane-bound COMT (MB-COMT) levels in placentas were increased by 2.5 fold in the full term vs. the first trimester placentas. Furthermore, 2-ME suppressed cell proliferation under $20 \% \mathrm{O}_{2}$ but not $2.5 \% \mathrm{O}_{2}$, while $2-\mathrm{ME}$ promoted cell migration under $2.5 \%$ but not $20 \% \mathrm{O}_{2}$ in vitro. Conclusion: Considering $2.5 \% \mathrm{O}_{2}$ is a state more closely mimicking in vivo condition, these data suggest a decrease in 2-ME levels may inhibit trophoblast cell migration, possibly leading to PE.

Z. Shen and Y. Wu contributed equally to this work.

Kai Wang, M.D., Ph.D., and Tao Duan, M.D., Ph.D.,
Clinical and Translational Research Center, and Department of Obstetrics, Shanghai First Maternity and Infant Hospital, Tongji University School of Medicine No.536, Chang Le Road, Jing An District, Shanghai 200040 (P.R. China)

E-Mail kaiwangcn@yahoo.com and E-Mail tduan@yahoo.com 


\section{Introduction}

Preeclampsia (PE), a pregnancy-specific disease characterized by hypertension and proteinuria, remains to be one of the major causes of maternal and fetal morbidity, mortality and preterm birth, affecting 2-8\% of all pregnant women [1]. The etiopathogenesis of PE has not been fully elucidated; however, it is well recognized that PE is associated with impaired trophoblast invasion in early pregnancy [2], producing the subsequent oxidative stress and angiogenic imbalance that contribute to the development of endothelial dysfunction in the later gestation period of $\mathrm{PE}$ patients [3-5].

2 -methoxyestradiol (2-ME) is a natural metabolite of $17 \beta$-estradiol, which is generated by catechol-O-methyltransferase (COMT) [6-9]. This enzyme is widely distributed in many mammalian tissues including liver, kidney, brain and placenta [10,11]. Recent evidence has demonstrated that 2-ME under low-oxygen conditions is critical for the proper cytotrophoblast invasion, placental vascular development and regulation of oxygen tension during normal pregnancy; therefore, impaired 2-ME synthesis/release has been implicated in the etiopathogenesis of PE $[2,5,6]$. In support of this concept, Kanasaki et al. has also reported that COMT-deficient mice exhibit a PE-like phenotype and placental hypoxia in pregnancy [7], and such PE-like features could be rescued by subcutaneous injection of 2-ME, further confirming the major roles of COMT/2-ME interactions in PE.

Previous studies have demonstrated that circulating 2-ME levels are low (18-138 pg/ $\mathrm{ml}$ or $0.059-0.46 \mathrm{nM}$ ) in non-pregnant women and dramatically increase during pregnancy (216-10,690 pg/ml or 0.72-35.4 nM) [12-15]. Meanwhile, Jobe et al. (2013) recently reported mean maternal plasma 2-ME levels $(2186 \mathrm{pg} / \mathrm{ml}, \sim 7 \mathrm{nM})$ in normotensive full term pregnant women was significantly higher than those in mild PE (mPE, $1813 \mathrm{pg} / \mathrm{ml}, 6 \mathrm{nM})$ and severe PE (sPE, $982 \mathrm{pg} / \mathrm{ml}, 3 \mathrm{nM}$ ) as 2-ME was measured using liquid chromatography mass spectrometry [16]. In addition, another study showed that 2-ME levels in plasma at the first trimester (11-14th weeks) from women who developed PE later in pregnancy were significantly lower $(1.9 \pm 2.0$ vs. $61.7 \pm 27 \mathrm{pg} / \mathrm{ml}, \sim 0.006 \mathrm{nM}$ vs. $0.204 \mathrm{nM})$ than those in normal controls [8]. However, little information is available regarding changes in serum levels of 2-ME during the first, second, and third trimester of pregnancy, and in the patients with $\mathrm{mPE}$ and sPE compared with gestational age-matched normotensive controls, as well as the molecular mechanisms underlying these changes. Similarly, the distribution and expression of COMT in the placenta and its association with $\mathrm{MPE}$ and SPE still remain poorly studied.

Considering the alteration of maternal 2-ME levels in preeclampsia patients, we hypothesize that 2-ME is potentially involved in the occurrence of preeclampsia by interfere with the biological behaviors of trophoblasts. Therefore, the aim of this study was to determine the levels of maternal serum 2-ME during normal pregnancy, also in the patients with $\mathrm{mPE}$ and $\mathrm{sPE}$, as well as its effects on the trophoblast cell proliferation and migration under either nomorxia $\left(20 \% \mathrm{O}_{2}\right)$ or hypoxia $\left(2.5 \% \mathrm{O}_{2}\right)$ to test our hypothesis that altered serum 2-ME levels may result in the impaired trophoblast functions in preeclampsia. We also investigated the placental COMT expression and/or distribution in the first trimester and full term as well as those in the patients with $\mathrm{MPE}$ and sPE to further explore the mechanisms responsible for the altered 2-ME levels in preeclampsia.

\section{Materials and Methods}

\section{Patients and samples collection}

Maternal blood samples from patients in different trimesters of pregnancy, patients diagnosed with mPE and sPE, and non-pregnancy were collected in vacutainer tubes without EDTA for serum separation. Patients' ages were similar between these groups. The samples were centrifuged at $4^{\circ} \mathrm{C}$ with a relative centrifugal force of $1500 \times \mathrm{g}$ for $10 \mathrm{~min}$. The supernatant serum samples were transferred to clean $1.5 \mathrm{ml}$ Eppendorf tubes and stored at $-80^{\circ} \mathrm{C}$ for EIA (Enzyme Immunoassay) analysis. Preeclampsia was defined according to the guidelines of the US National Institutes of Health (US National High Blood Pressure Education 
Program 2000). Preeclampsia was considered severe if one or more of the following criteria were present: maternal blood pressure higher than or equal to $160 / 110 \mathrm{mmHg}$ on two separate readings; proteinuria more than $2+$ by dipstick or more than $2 \mathrm{~g} / 24 \mathrm{~h}$; visual disturbances; pulmonary edema; epigastric or right upper quadrant pain; impaired liver function; thrombocytopenia; or fetal growth restriction $[1,17]$. Preterm is defined as a delivery before 37 weeks of gestation. All the preterm patients exhibited spontaneous preterm labor and/or premature rupture of membranes without evidence of infection (microbiological culture investigations and histopathological examinations), proteinuria, hypertensive disease or maternal co-morbidities [18].

Placental tissues were obtained from a portion of normal ( $39 \pm 0.3 \mathrm{wks}, \mathrm{n}=7), \mathrm{mPE}(39 \pm 0.5 \mathrm{wks}, \mathrm{n}=$ 8) and sPE patients ( $36 \pm 1.3 \mathrm{wks}, \mathrm{n}=7)$ and obtained immediately ( $<30$ mins) after delivery by caesarean section. Small pieces $\left(\sim 0.5 \mathrm{~cm}^{3}\right)$ were cut from the fetal part of the placentas under the aseptic conditions and washed briefly in sterile PBS to remove maternal blood contamination. The chorionic villi samples in the first trimester of pregnancy $(7.12 \pm 0.24 \mathrm{wks})$ were obtained and dissected out immediately after vacuum aspiration and washed in sterile PBS. All samples were frozen within 15 minutes of delivery and stored in liquid nitrogen for Western blot analysis. Additional placental tissues from first trimester and third trimester were fixed at $4{ }^{\circ} \mathrm{C}$ using $4 \%$ paraformaldehyde in $10 \mathrm{mM}$ PBS within 24 hours and embedded them in paraffin for immunohistochemistry (IHC).

The collection of blood and placental samples were approved by the Scientific and Ethical Committee of the Shanghai First Maternity and Infant Hospital affiliated with Tongji University. All of the samples were collected with a written informed consent provided by the participants.

\section{2-ME measurement}

Maternal 2-ME levels in serum were determined using a human 2-ME EIA kit (Cayman Chemical Company, No.582261, Ann Arbor, MI) according to the manufacturer's instructions. The detection limit of 2-ME was approximately $40 \mathrm{pg} / \mathrm{ml}$. Samples were added with internal standard working solution, incubated at $4{ }^{\circ} \mathrm{C}$ overnight and followed by several cleanup steps. The samples in the 96-well plate were read at $405 \mathrm{~nm}$ with a microplate reader (MULTISKAN MK3, Thermo Scientific, Rockford, IL). The concentrations of 2-ME were calculated based on the standard curve.

IHC

Immunolocalization of COMT in the placental tissues was visualized by indirect detection via the avidin:biotinylated-peroxidase complex method (Vector Laboratories, Burlingame, CA) as described [19]. Tissue sections $(5 \mu \mathrm{m})$ were deparaffinized and dehydrated. Endogenous peroxidase activity was quenched by immersing the tissue sections in $3 \% \mathrm{H}_{2} \mathrm{O}_{2}$ in methanol for $10 \mathrm{~min}$. After blocking the non-specific binding with $1 \%$ horse serum albumin for $20 \mathrm{~min}$, the tissue sections were probed with a rabbit anti-COMT antibody (1:2000, Chemicon International, No. AB5873, Billerica, MA). Rabbit preimmune IgG (1:2000, Kangchen, No. KC-RB-035, Shanghai, CHN) was used as the negative control.

\section{Western blot analysis}

Total placental tissue lysates were prepared by homogenization as previously described $[19,20]$. The extracted protein concentration was measured with BCA Protein Assay Kit (Thermo Scientific). $20 \mu$ g proteins were separated on 10\% SDS-PAGE gels. Proteins were transferred to polyvinylidene difluoride membranes (Roche Diagnostics, No. IPVH00010, Indianapolis, IN). After blocking (5\% milk in TBST, 0.1\% Tween-20) in room temperature for $1 \mathrm{~h}$, the membranes were probed with rabbit anti-human COMT antibody (1:15000; Chemicon International, No. AB5873), and anti-glyceraldehyde-3-phosphate dehydrogenase (GAPDH; 1:5000; Kangchen, No. KC-5G4) as an endogenous loading control, respectively. Proteins were visualized using enhanced chemiluminescence reagents (Thermo Scientific, No. KC-5G4) and the immunoreactive signals were analyzed by densitometry using the Image-J imaging analysis software (NIH, Bethesda, MD).

\section{Cell Proliferation and Migration}

To explore the role of 2-ME in trophoblast cells, cell proliferation and migration were conducted using human trophoblast (HTR-8/SVneo) cell line, originally obtained from Dr. Charles H. Graham (Queen's University, Ontario, Canada) as described [21, 22]. The HTR-8/SVneo cell, an immortalized extravillous cell line, is widely used as a trophoblast cell model for studying normal trophoblast function. HTR-8/SVneo 
cells were cultured in DMEM/F12 (MEM, Gibco, No. 11330, Grand Island, NY) supplemented with 10\% fetal bovine serum (FBS; Gibco, No. 10099) and antibiotics (100 U/ml penicillin [P] and $100 \mathrm{mg} / \mathrm{ml}$ streptomycin [S]; Gibco, No. 15140). All cells were incubated at $37^{\circ} \mathrm{C}$ in a humidified atmosphere containing $5 \% \mathrm{CO}_{2}$.

For the cell proliferation assay, cells seeded in 96-well plates (2000 cells/well) were cultured in DMEM/ F12 media. After 16h, attached cells were treated with different concentrations of 2-ME (0-100 nM; Tocris, No. 1807, Ballwin, MO) in media supplemented with 10\% FBS and 1\% P/S under nomoxia (20\% oxygen) or hypoxia (2.5\% oxygen) for up to 48 hours. The number of cells was determined using the crystal violet method. Wells containing known cell numbers $(0,1000,2000,5000,10,000,20,000$ or 40,000 cells/well; 6 wells/cell density) were treated in the similar fashion to establish standard curves. Four independent experiments were run for the cell proliferation assay.

Cell migration was evaluated using a 24-Multiwell BD Falcon FluoroBlok Insert System (8.0 $\mu$ m pores; BD Biosciences, San Jose, CA). After treatment without or with $100 \mathrm{nM}$ 2-ME under normoxic or hypoxic condition for $48 \mathrm{hr}$, cells $(100,000$ cells/well) were seeded into the insert (topside of membrane) in the DMEM/F12 media with 1\% FBS. The bottom wells of the chamber were filled with DMEM/F12 media with $10 \%$ FBS. After $16 \mathrm{~h}$ treatment without or with $100 \mathrm{nM} 2$-ME under normoxic or hypoxic condition, cells that migrated to the bottom of the inserts were stained with calcein AM $(0.2 \mu \mathrm{g} / \mathrm{ml}$; Invitrogen, No. C3100MP) for 30 min, examined and recorded by an inverted microscope mounted with a CCD camera. The numbers of migrated cells were counted using the MetaMorph image analysis software (Molecular Devices, Sunnyvale, CA).

\section{Statistical analysis}

Values are presented as mean \pm S.E.M. unless otherwise indicated. All statistics were performed with SigmaStat, version 3.5 (Jandel Co., San Rafael, CA), applying one way ANOVA followed by Fisher LSD method for clinical characteristics, 2-ME concentration and cells proliferation comparison; two way ANOVA followed by Bonferroni t-test for Western blot analysis; and Student's t-test for cells migration comparison. Significant differences were considered when $p<0.05$.

\section{Results}

Serum 2-ME levels were elevated with the progression of pregnancy

There is no significant difference of maternal age in patients with non-pregnancy (28 \pm 1.0 year, $n=15)$, first trimester $(26 \pm 1.2$ year, $n=10)$, second trimester $(28 \pm 0.9$ year, $n=10)$ and third trimester $(28 \pm 0.7$ year, $n=9)$ of normal pregnancy without delivery. The maternal serum 2-ME concentrations were notably higher in the third trimester $(281 \pm 26.1 \mathrm{pg} / \mathrm{ml}, p$ $<0.05)$ than those in the first $(188 \pm 23.5 \mathrm{pg} / \mathrm{ml})$, second trimester $(152 \pm 6.8 \mathrm{pg} / \mathrm{ml})$ and non-pregnancy women (148 $\pm 14.7 \mathrm{pg} / \mathrm{ml}$ ) (Fig. 1A), indicating that 2-ME concentrations is increasing with the progression of pregnancy.

\section{Serum 2-ME levels were lower in patients with $M P E$ and $S P E$}

The clinical characteristics from full term, preterm, mPE and sPE patient are shown in Table 1. No significant discrepancies were observed in the maternal age among all four groups studied. Consistent with previous epidemiologic studies [23], patients with sPE and preterm had smaller ( $p \leq 0.001)$ gestational ages and lower fetal weights $(p \leq 0.001)$ compared to the full term. Serum 2-ME concentrations were significantly decreased in both mPE (330 \pm $30.2 \mathrm{pg} / \mathrm{ml}, p=0.024)$ and $\mathrm{sPE}(290 \pm 23.4 \mathrm{pg} / \mathrm{ml}, p=0.001)$ than those in the term control (428 $\pm 29.1 \mathrm{pg} / \mathrm{ml}$, Fig. 1B). By contrast, no marked alteration was observed between sPE and preterm control $(273 \pm 13.8 \mathrm{pg} / \mathrm{ml}, p=0.703$, Fig. $1 \mathrm{~B})$, which probably contributed to the lower levels in preterm controls when compared to term controls.

\section{COMT protein was present in the human placentas}

IHC was performed to localize COMT in the human placentas. Positive brownish staining for COMT was observed primarily in both the syncytiotrophoblast and cytotrophoblast layers from the first trimester pregnancy and in the syncytiotrophoblast layer and villous stroma cells of the placentas from full term pregnancy (Fig. 2). 


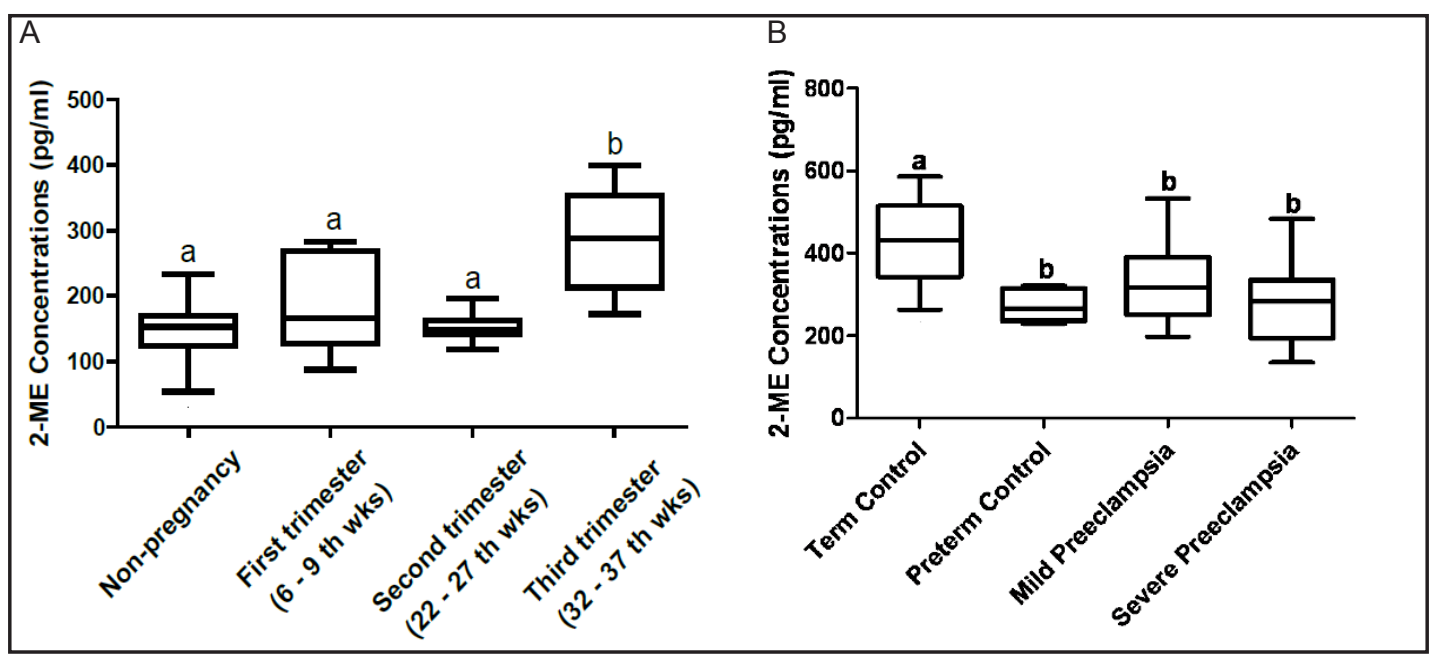

Fig. 1. Serum 2-ME concentrations during first trimester, second trimester and third trimester of normal pregnant women and nonpregnant women (A) and in women with normortensive term, preterm and PE pregnancies (B). Serum 2-ME was measured using EIA. For each group, the line in the middle of the box denotes the median. The upper and the lower edges of the box represent the $25^{\text {th }}$ and $75^{\text {th }}$ percentiles, respectively. The lines extending from each side of the box covering the extent of the data on $1.5 \times$ interquartile range. ${ }^{a, b}$ Mean with different letters differ (one way ANOVA, $p<0.05$ ).

Table 1. Characteristics of patients with normal term, preterm, and PE. All the data were expressed as mean \pm S.E.M.. a,b,c Mean with different letters differ (one way ANOVA, $p<0.05$ )

\begin{tabular}{lcccc}
\hline & $\begin{array}{c}\text { Term } \\
(\mathrm{n}=16)\end{array}$ & $\begin{array}{c}\text { Preterm } \\
(\mathrm{n}=8)\end{array}$ & $\begin{array}{c}\mathrm{mPE} \\
(\mathrm{n}=13)\end{array}$ & $\begin{array}{c}\mathrm{sPE} \\
(\mathrm{n}=28)\end{array}$ \\
\hline Patient age (years) & $28 \pm 0.7^{\mathrm{a}}$ & $32 \pm 2.1^{\mathrm{a}}$ & $31 \pm 1.3^{\mathrm{a}}$ & $30 \pm 0.5^{\mathrm{a}}$ \\
Gestation age (weeks) & $39 \pm 0.4^{\mathrm{a}}$ & $36 \pm 0.2^{\mathrm{b}}$ & $38 \pm 0.4^{\mathrm{a}, \mathrm{c}}$ & $36 \pm 0.6^{\mathrm{b}, \mathrm{c}}$ \\
Systolic pressure(mmHg) & $120 \pm 2.7^{\mathrm{a}}$ & $119 \pm 3.6^{\mathrm{a}}$ & $143 \pm 3.3^{\mathrm{b}}$ & $158 \pm 4.1^{\mathrm{c}}$ \\
Diastolic pressure(mmHg) & $76 \pm 2.2^{\mathrm{a}}$ & $76 \pm 1.9^{\mathrm{a}}$ & $97 \pm 2.3^{\mathrm{b}}$ & $98 \pm 1.6^{\mathrm{b}}$ \\
Proteinuria & - & - & $+\sim++$ & $++\sim++++$ \\
Fetal weights (g) & $3342 \pm 97.0^{\mathrm{a}}$ & $2633 \pm 92.5^{\mathrm{b}}$ & $3476 \pm 186.6^{\mathrm{a}}$ & $2694 \pm 167.4^{\mathrm{b}}$ \\
\hline
\end{tabular}

Fig. 2. Immunohistochemical localization of COMT in first trimester (A) and third trimester placentas (B). Brownish color indicates positive staining for COMT. Arrows, syncytiotrophoblasts; arrowheads, cytotrophoblasts; asterisks, villous stroma. Bars, 100 um.

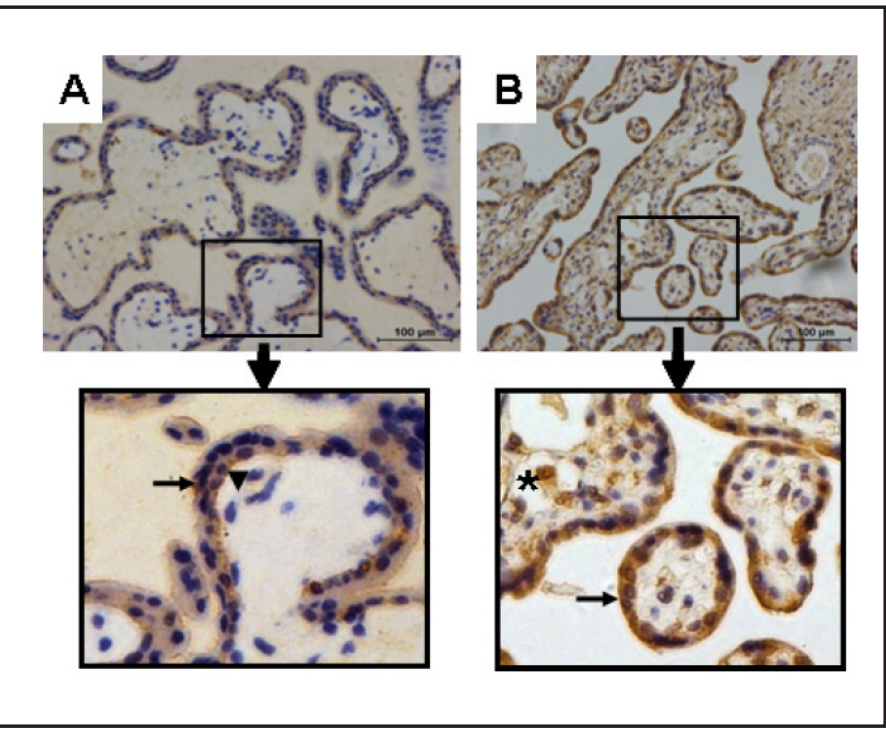

COMT protein levels were high in normal term placentas

Total placental COMT protein levels in different stages during pregnancy was investigated by Western blot analysis. We observed a significant elevation in soluble cytoplasmic COMT 
Fig. 3. Western blot analysis for COMT protein in human placentas from normal pregnancies. Placentas were obtained from the first trimester $(n=11)$ and full term placenta $(\mathrm{n}=10)$. Representative Western blots are shown for COMT and GAPDH. Data are normalized to GAPDH are expressed as mean \pm S.E.M. fold of MB-COMT expression in first trimester placentas (two way ANOVA, ${ }^{*} p<0.05$, $\left.{ }^{* *} p<0.001\right)$.

Fig. 4. Western blot analysis for COMT protein in human placentas from normotensive and PE women. Placentas were collected from normotensive $(\mathrm{n}=7)$, mPE $(\mathrm{n}=8)$ and $\mathrm{sPE}$ ( $n=7)$ pregnancies. Representative Western blots are shown for COMT and GAPDH. Data are normalized to GAPDH are expressed as mean \pm S.E.M. fold of MB-COMT expression in term control placentas (two way ANOVA, $p>0.05$ ).
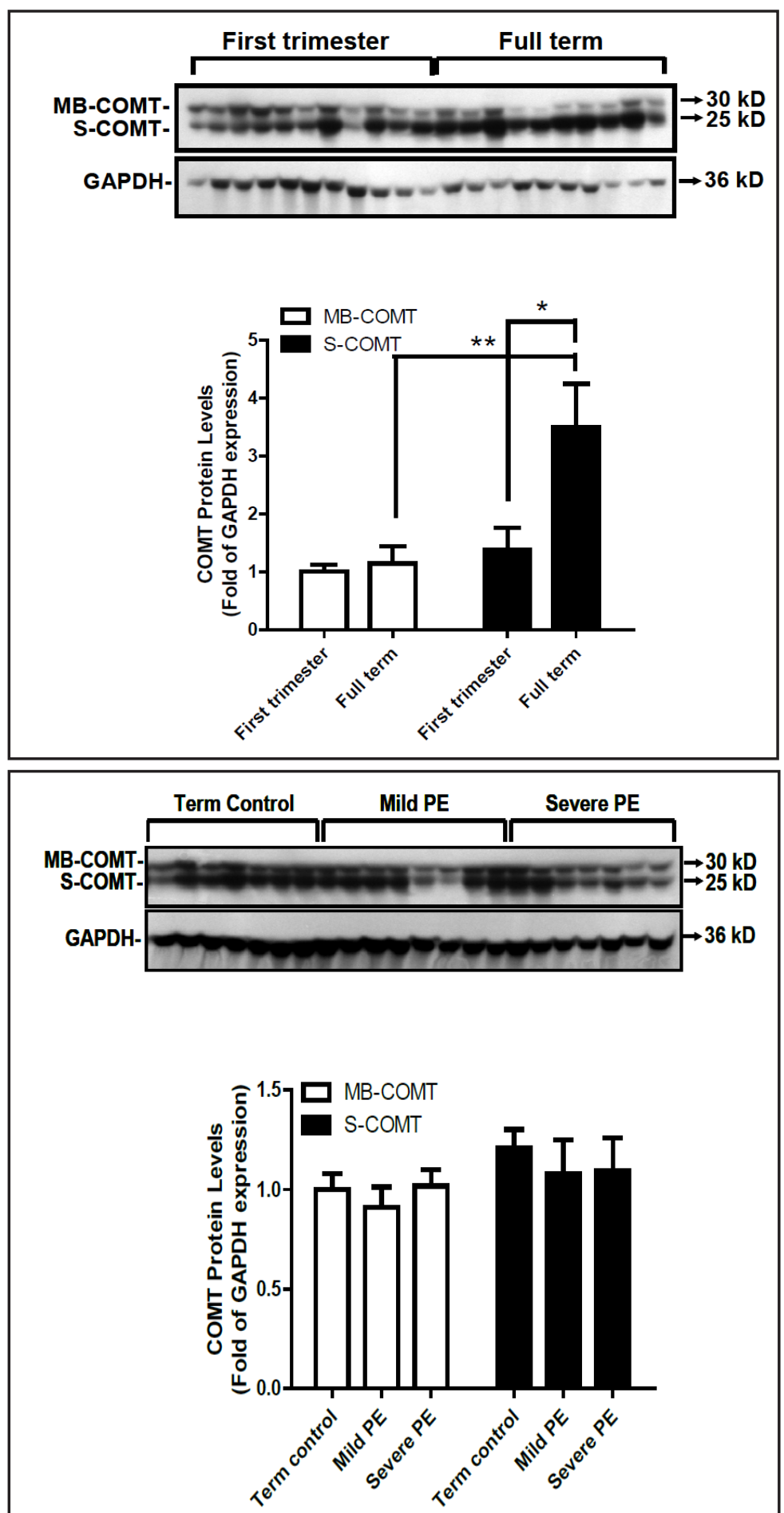

(S-COMT), but not membrane-bound COMT (MB-COMT) in the full term pregnancies as compared with those in first trimester pregnancies ( $p=0.001$; Fig. 3). In addition, the ratio of placental S-COMT to MB-COMT in the first trimester $(1.4 \pm 0.2)$ and full term pregnancies $(3.1 \pm 0.5)$ revealed that the placental S-COMT protein levels were significantly higher than MB-COMT in full term pregnancies ( $p<0.001$; Fig. 3 ), implying that S-COMT is a predominant form of COMT in placentas during normotensive pregnancy. However, no marked alterations in S- and MB-COMT protein levels were observed between $\mathrm{MPE}$ and SPE as compared with full term pregnancies (Fig. 4). 
Fig. 5. Effects of 2-ME on HTR-8/SVneo cell proliferation under normoxia or hypoxia. Cells seeded in 96-well plates (2000 cells/well) were treated without (control) or with 2-ME for 2 days under normoxic or hypoxic condition. Data are expressed as mean \pm S.E.M. fold of the control from four independent experiments. Number of cells per well in the control were $5856 \pm 589$ and $5217 \pm 724$ on day 2 under normxic and hypoxic conditions, respectively. Asterisks indicate significant (one way ANOVA, ${ }^{* *} p<0.001$ ) differences from the control under either $20 \% \mathrm{O}_{2}$ or $2.5 \% \mathrm{O}_{2}$ condition.

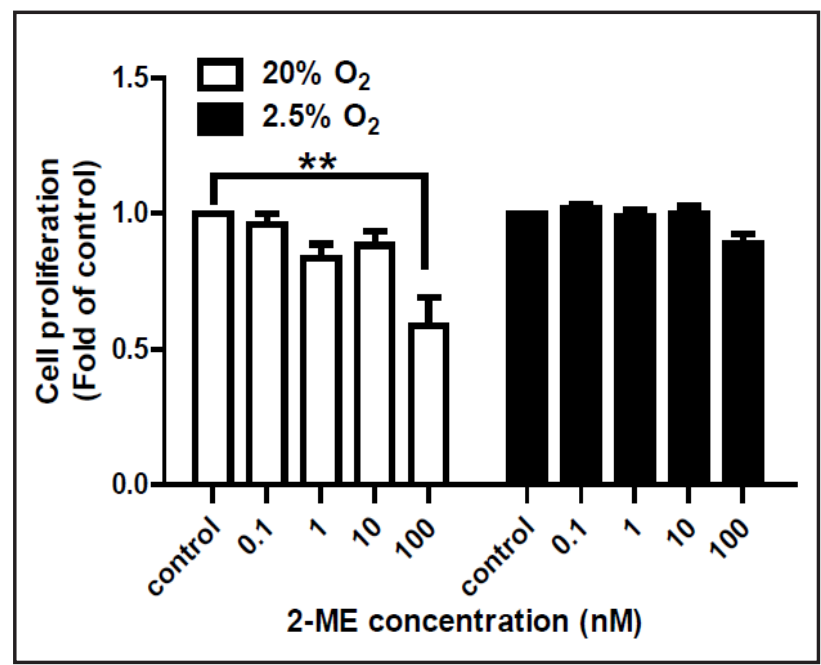

2-ME concentration (nM)

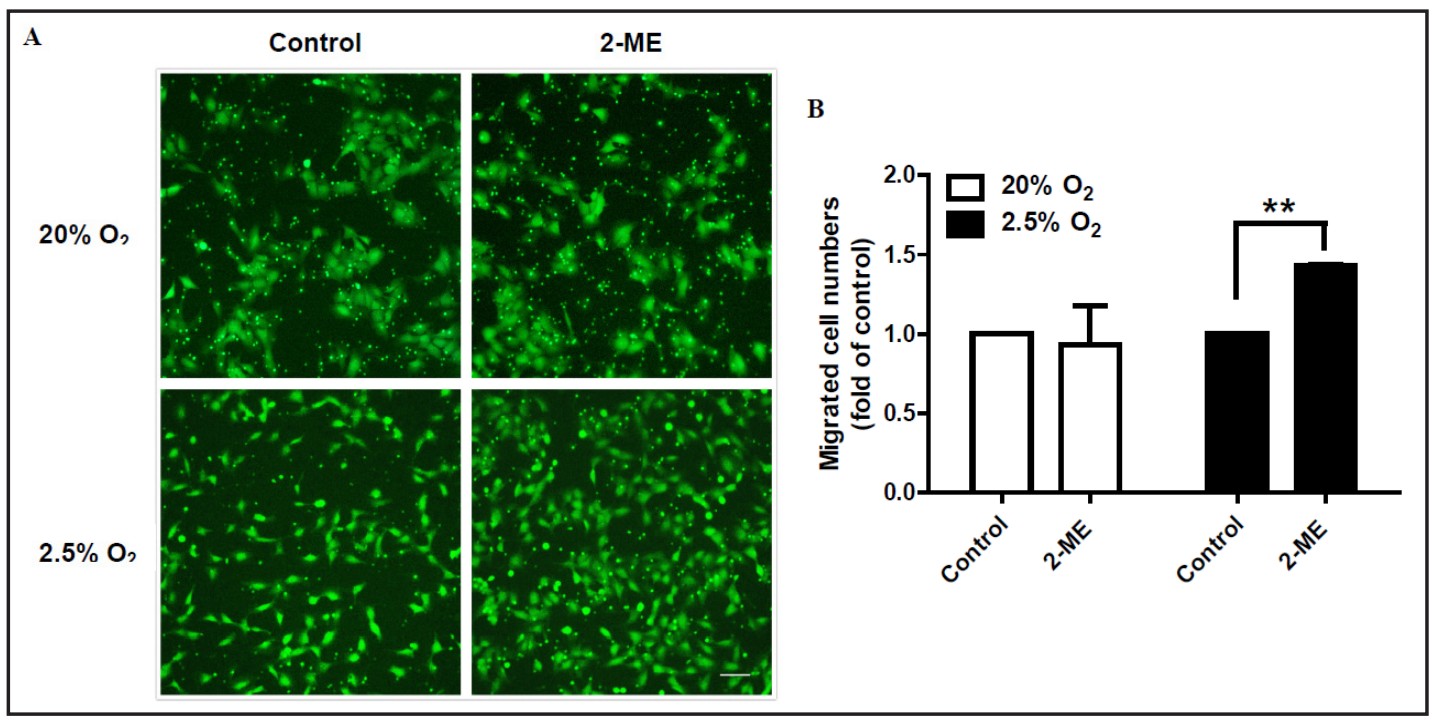

Fig. 6. Effects of 2-ME on HTR-8/SVneo cell migration under normoxia or hypoxia. The cells suspended in serum-free DMEM/F12 were overlaid in the upper chamber of each transwell. After incubation with 2-ME $(100 \mathrm{nM})$ for $16 \mathrm{hrs}$ under normoxic or hypoxic condition, the penetrating cells were stained with calcein AM and recorded under a microscope mounted with a charge-coupled device camera. A) Photographs depict the migration of HTR-8/SVneo cells; B) quantitative data are expressed as mean \pm S.E.M. fold of the control from three independent experiments. Asterisks indicate significant (Student's t-test, ${ }^{*} p<0.001$ ) differences from the control under either $20 \% \mathrm{O}_{2}$ or $2.5 \% \mathrm{O}_{2}$ condition.

\section{2-ME under normoxia and hypoxia differentially affect HTR-8/SVneo cell proliferation and migration}

To examine the role of 2-ME in regulating the placental cell function in normoxic and hypoxic conditions, we determined the effects of 2-ME on trophoblast cell proliferation and migration using HTR-8/SVneo cells as a cell model (Figs. 5 and 6). We found that 2-ME at $100 \mathrm{nM}$ concentration significantly suppressed HTR-8/SVneo cells proliferation under normoxia $(p<0.001)$, but no such effect was observed under hypoxia $(p=0.08)$. In addition, 2-ME at physiological concentrations ( $0.1 \mathrm{nM}-10 \mathrm{nM})$ did not interfere with HTR-8/SVneo cells proliferation under neither normoxia nor hypoxia (Fig. 5). Furthermore, 2-ME at 100 nM contration did not affect HTR-8/SVneo cells migration under normoxia; however, such migration was significantly induced under hypoxia $(p<0.001$, Fig. 6). 


\section{Discussion}

In this study we demonstrated that maternal serum 2-ME levels were increased from non-pregnancy state and early pregnancy to later pregnancy. We found that 2-ME levels were decreased in patients with $\mathrm{MPE}$ and $\mathrm{SPE}$ as compared to the normotensive full term control. Meanwhile preterm controls had lower levels of 2-ME than full term controls. More importantly, these increases in maternal serum 2-ME levels during normal pregnancy are associated with the elevated placental COMT protein levels; however, these decreases in 2-ME in $\mathrm{mPE}$ and sPE are not accompanied by the reduction in placental COMT. Lastly, we also showed that 2-ME only at its high pharmacological (100 nM) suppressed cell proliferation under $20 \% \mathrm{O}_{2}$ but not $2.5 \% \mathrm{O}_{2}$. Also 2-ME (100 $\mathrm{nM}$ ) under $2.5 \% \mathrm{O}_{2}$ but not $20 \% \mathrm{O}_{2}$ enhanced cell migration in vitro.

In the current study, we determined the levels of maternal serum 2-ME during different trimesters of normal pregnancy and non-pregnancy state. More importantly, we found 2-ME was elevated from the third trimester of normal human pregnancies, while there were no significant difference in the first trimester, second trimester of normal pregnancy and nonpregnancy state. The serum 2-ME values measured using EIA are within the physiological range previously reported [24-26]. Although these values in the full term and PE are approximately 5 fold lower than those detected by liquid chromatography mass spectrometry [24], these discrepancies are likely contributed to the different analysis methods used. Our current results are in agreement with previous observations that 2-ME concentrations were notably higher in the full term than those in non-pregnancy state [7], and also provide new evidence showing serum 2-ME levels were elevated during the third trimester of normal pregnancy.

The decreased 2-ME in mPE and sPE observed in the current study is consistent with the report by Jobe et al. as compared with full term pregnancy [24]. Thus, despite that mPE and SPE may have different pathogenesis [21,22], both $\mathrm{mPE}$ and SPE are associated with similar decreases in maternal serum 2-ME levels. These data suggest that such decreases might be their common features, and may serve as a serum diagnostic marker for PE in conjunction with other clinical diagnosis. More importantly, in the current study we firstly reported that no significant difference was detected between $\mathrm{SPE}$ and preterm controls when considered the same gestation age. Based on our present data that maternal serum 2-ME was increased as the gestational ages advanced, we cannot exclude the possibility that lower 2-ME levels in SPE could attribute to the short GAs. However, multiple factors may cause 2-ME levels decrease in preeclampsia except for gestation ages, especially for the synthesis and degradation pathways of 2-ME, which are still unresolved.

It is well demonstrated that COMT mRNA encoded both S-COMT and MB-COMT [10], the former of which is responsible for the $O$-methylation of catecholamine neurotransmitters [27], and the latter eliminates exogenous catechol compounds [10,11]. Moreover, previous studies have revealed that S-COMT is a predominant form of COMT expressed in human tissues [28, 29]. We also showed that S-COMT is the major isoform of COMT in human placentas and is mainly expressed in the syncytiotrophoblast, cytotrophoblast and villous stroma cells, indicating that placental 2-ME are primarily synthesized in these placental cells. Moreover, our current observation showing in parallel with the increases of 2-ME, the increased ratio of S-COMT to MB-COMT from the first trimester and full term pregnancies with the progression of GAs is novel, further suggesting that placental S-COMT is a major source contributing to the increase in maternal serum 2-ME. Interestingly, the decreased serum 2-ME levels were not accompanied by the decreased placental COMT protein levels in $\mathrm{mPE}$ and $\mathrm{SPE}$, which is in agreement with a recent report demonstrating that placental COMT expression was not altered in SPE compared to term or preterm normotensive pregnancies [9]. Except for COMT, other possible factors could be involved in this imbalance. Alterations in the $17 \beta$-estradiol synthetic pathway during pregnancy could explain that 2 -ME can be regulated by other enzymes. For example, aromatase is not only responsible for the production of $17 \beta$-estradiol, but is also a rate-limiting enzyme in the synthesis of 2 -ME 
[30]. The alterations in the functionality or bioavailability of aromatase may impact the levels of 2-ME. Indeed, the placental aromatase has been observed deficient in preeclampsia from recent study [31]. In addition, the decreased in both total plasma and albumin proteins in preeclamptic patients [32] may also contribute to the low levels of circulating 2-ME in preeclampsia.

It is well known that preeclampsia is closely associated with impaired trophoblast invasion in early pregnancy [2]. Until now, little has been known about the effects of 2-ME on the trophoblast cells proliferation and migration. Only one study reported that under $2.5 \% \mathrm{O}_{2}$, but not $17 \% \mathrm{O}_{2}, 2-\mathrm{ME}$ at $500 \mathrm{nM}$ concentration significantly induced HTR-8/ SVneo cells migration [6]. Our current study demonstrated that under $20 \% \mathrm{O}_{2}$ but not 2.5\% $\mathrm{O}_{2}$, 2-ME suppressed HTR-8/SVneo cells proliferation, and 2-ME enhanced HTR-8/ SVneo cells migratory ability under $2.5 \% \mathrm{O}_{2}$ in vitro, suggesting that oxygen environment is a pivotal determinants on trophoblast function [33]. Indeed, under hypoxic condition 2-ME downregulated HIF-1 $\alpha$ level and its downstream target genes, which deeply involved in the cell growth based on recent study [34]. Additionally, in the present study 2-ME only at a pharmacological concentration but not at physiological levels inhibits trophoblast cell proliferation. Similarly, other than trophoblast cells, high 2-ME also regulate growth and function of other placental cells. For example, 2-ME at high concentrations ( $\geq 100 \mathrm{nM}$ ) has antiangiogenic effects via inhibition of endothelial proliferation [35-37] and cell permeability $[38,39]$. It seems that 2-ME's effects on placental cells' functions are highly dependent on the concentrations used. To date, it is unknown if decreases in maternal serum 2-ME during PE have adverse effects on both of these cells function. On the other hand, increasing evidence has demonstrated that 2-ME may prevent structural damage of vascular endothelial cells during preeclampsia [7], which may be mediated by suppressing hypoxia inducible factor$1 \alpha$-mediated inflammation $[7,40,41]$ as well as free radicals- and oxidized LDL-induced injury $[25,42]$. Therefore, maintaining serum 2-ME concentrations within the normal range during pregnancy might be important in protecting against PE.

In this study, we observed that maternal serum 2-ME levels increased significantly in the third trimester of normal pregnancy; however, serum levels of 2-ME were lower in patients with clinical PE when compared to normotensive pregnancies. To date, there are questions around COMT/2-ME signaling in the occurrence of PE. Thus, 2-ME may have importance as a serum/plasma diagnostic marker of preeclampsia, and may also serve as a therapeutic supplement to prevent or treat preeclampsia. Better understanding of COMTand 2-ME-related mechanisms would help us to visualize the development of pregnancyrelated disorders such as $\mathrm{PE}$, in order to explore effective strategies.

\section{Disclosure Statement}

The authors declare that they have no competing interests.

\section{Acknowledgements}

This research was supported in part by National Natural Science Foundation of China No. 81471461 (to T.D.) and No.81270703 (to K.W.), and Shanghai Pujiang Program No. 12PJ1407300 (to K.W.).

\section{References}

1 Steegers EA, von Dadelszen P, Duvekot JJ, Pijnenborg R: Pre-eclampsia. Lancet 2010;376:631-644.

-2 Shenoy V, Kanasaki K, Kalluri R: Pre-eclampsia: connecting angiogenic and metabolic pathways. Trends Endocrinol Metab 2010;21:529-536. 
3 Solomon CG, Seely EW: Preeclampsia - Searching for the cause. New Engl J Med 2004;350:641-642.

4 Roberts JM, Gammill HS: Preeclampsia: recent insights. Hypertension 2005;46:1243-1249.

5 Perez-Sepulveda A, Espana-Perrot PP, Norwitz ER, Illanes SE: Metabolic pathways involved in 2-methoxyestradiol synthesis and their role in preeclampsia. Reprod Sci 2013;20:1020-1029.

-6 Lee SB, Wong AP, Kanasaki K, Xu Y, Shenoy VK, McElrath TF, Whitesides GM, Kalluri R: Preeclampsia: 2-methoxyestradiol induces cytotrophoblast invasion and vascular development specifically under hypoxic conditions. Am J Pathol 2010;176:710-720.

7 Kanasaki K, Palmsten K, Sugimoto H, Ahmad S, Hamano Y, Xie L, Parry S, Augustin HG, Gattone VH, Folkman J, Strauss JF, Kalluri R: Deficiency in catechol-0-methyltransferase and 2-methoxyoestradiol is associated with pre-eclampsia. Nature 2008;453:1117-1121.

8 Perez-Sepulveda A, Torres MJ, Valenzuela FJ, Larrain R, Figueroa-Diesel H, Galaz J, Nien JK, Serra R, Michea L, Illanes SE: Low 2-methoxyestradiol levels at the first trimester of pregnancy are associated with the development of pre-eclampsia. Prenat Diagn 2012;32:1053-1058.

-9 Palmer K, Saglam B, Whitehead C, Stock O, Lappas M, Tong S: Severe early-onset preeclampsia is not associated with a change in placental catechol O-methyltransferase (COMT) expression. Am J Pathol 2011;178:2484-2488.

10 Mannisto PT, Kaakkola S: Catechol-O-methyltransferase (COMT): biochemistry, molecular biology, pharmacology, and clinical efficacy of the new selective COMT inhibitors. Pharmacol Rev 1999;51:593-628.

11 Myohanen TT, Schendzielorz N, Mannisto PT: Distribution of catechol-0-methyltransferase (COMT) proteins and enzymatic activities in wild-type and soluble COMT deficient mice. J Neurochem 2010;113:1632-1643.

12 Berg D, Sonsalla R, Kuss E: Concentrations of 2-methoxyoestrogens in human serum measured by a heterologous immunoassay with an 125I-labelled ligand. Acta Endocrinol (Copenh) 1983;103:282-288.

-13 Dragun D, Haase-Fielitz A: Low catechol-0-methyltransferase and 2-methoxyestradiol in preeclampsia: more than a unifying hypothesis. Nephrol Dial Transplant 2009;24:31-33.

14 Barnes CM, McElrath TF, Folkman J, Hansen AR: Correlation of 2-methoxyestradiol levels in cord blood and complications of prematurity. Pediatr Res 2010;67:545-550.

15 Dubey RK, Jackson EK: Potential vascular actions of 2-methoxyestradiol. Trends Endocrinol Metab 2009;20:374-379.

16 Jobe SO, Tyler CT, Magness RR: Aberrant synthesis, metabolism, and plasma accumulation of circulating estrogens and estrogen metabolites in preeclampsia implications for vascular dysfunction. Hypertension 2013;61:480-487.

17 Practice ACoO: ACOG practice bulletin. Diagnosis and management of preeclampsia and eclampsia. Number 33, January 2002. American College of Obstetricians and Gynecologists. Int J Gynaecol Obstet 2002;77:6775.

18 Goldenberg RL, Culhane JF, Iams JD, Romero R: Epidemiology and causes of preterm birth. Lancet 2008;371:75-84.

19 Jiang YZ, Wang K, Fang R, Zheng J: Expression of aryl hydrocarbon receptor in human placentas and fetal tissues. J Histochem Cytochem 2010;58:679-685.

20 Chung JY, Song Y, Wang Y, Magness RR, Zheng J: Differential expression of vascular endothelial growth factor (VEGF), endocrine gland derived-VEGF, and VEGF receptors in human placentas from normal and preeclamptic pregnancies. J Clin Endocrinol Metab 2004;89:2484-2490.

-21 Dai CF, Jiang YZ, Li Y, Wang K, Liu PS, Patankar MS, Zheng J: Expression and roles of Slit/Robo in human ovarian cancer. Histochem Cell Biol 2011;135:475-485.

22 Wang K, Song Y, Chen DB, Zheng J: Protein phosphatase 3 differentially modulates vascular endothelial growth factor- and fibroblast growth factor 2-stimulated cell proliferation and signaling in ovine fetoplacental artery endothelial cells. Biol Reprod 2008;79:704-710.

23 Sibai BM: Diagnosis and management of gestational hypertension and preeclampsia. Obstet Gynecol 2003;102:181-192.

24 Jobe SO, Ramadoss J, Koch JM, Jiang Y, Zheng J, Magness RR: Estradiol-17beta and its cytochrome P450- and catechol-0-methyltransferase-derived metabolites stimulate proliferation in uterine artery endothelial cells: role of estrogen receptor-alpha versus estrogen receptor-beta. Hypertension 2010;55:1005-1011.

25 Dubey RK, Tofovic SP, Jackson EK: Cardiovascular pharmacology of estradiol metabolites. J Pharmacol Exp Ther 2004;308:403-409. 
26 Lakhani NJ, Sparreboom A, Xu X, Veenstra TD, Venitz J, Dahut WL, Figg WD: Characterization of in vitro and in vivo metabolic pathways of the investigational anticancer agent, 2-methoxyestradiol. J Pharm Sci 2007;96:1821-1831.

27 Roth JA: Membrane-bound catechol-0-methyltransferase: a reevaluation of its role in the 0-methylation of the catecholamine neurotransmitters. Rev Physiol Biochem Pharmacol 1992;120:1-29.

-28 Tenhunen J, Salminen M, Lundstrom K, Kiviluoto T, Savolainen R, Ulmanen I: Genomic organization of the human catechol 0-methyltransferase gene and its expression from two distinct promoters. Eur J Biochem 1994;223:1049-1059.

-29 Hevir N, Sinkovec J, Rizner TL: Disturbed expression of phase I and phase II estrogen-metabolizing enzymes in endometrial cancer: lower levels of CYP1B1 and increased expression of S-COMT. Mol Cell Endocrinol 2011;331:158-167.

-30 Czajka-Oraniec I, Simpson ER: Aromatase research and its clinical significance. Endokrynol Pol 2010;61:126-134.

-31 Hertig A, Liere P, Chabbert-Buffet N, Fort J, Pianos A, Eychenne B, Cambourg A, Schumacher M, Berkane N, Lefevre G, Uzan S, Rondeau E, Rozenberg P, Rafestin-Oblin ME: Steroid profiling in preeclamptic women: evidence for aromatase deficiency. Am J Obstet Gynecol 2010;203:477. e471-479.

32 Baksu B, Baksu A, Davas I, Akyol A, Gulbaba G: Lipoprotein(a) levels in women with pre-eclampsia and in normotensive pregnant women. J Obstet Gynaecol Res 2005;31:277-282.

-33 Bowen RS, Gu Y, Zhang Y, Lewis DF, Wang Y: Hypoxia promotes interleukin-6 and -8 but reduces interleukin-10 production by placental trophoblast cells from preeclamptic pregnancies. J Soc Gynecol Investig 2005;12:428-432.

34 Mabjeesh NJ, Escuin D, LaVallee TM, Pribluda VS, Swartz GM, Johnson MS, Willard MT, Zhong H, Simons JW, Giannakakou P: 2ME2 inhibits tumor growth and angiogenesis by disrupting microtubules and dysregulating HIF. Cancer Cell 2003;3:363-375.

-35 Fotsis T, Zhang Y, Pepper MS, Adlercreutz H, Montesano R, Nawroth PP, Schweigerer L: The endogenous oestrogen metabolite 2-methoxyoestradiol inhibits angiogenesis and suppresses tumour growth. Nature 1994;368:237-239.

-36 Salih SM, Kapur A, Albayrak S, Salama SA, Magness RR: Pregnancy ameliorates the inhibitory effects of 2-methoxyestradiol on angiogenesis in primary sheep uterine endothelial cells. Reprod Sci 2011;18:858867.

-37 Reiser F, Way D, Bernas M, Witte M, Witte C: Inhibition of normal and experimental angiotumor endothelial cell proliferation and cell cycle progression by 2-methoxyestradiol. Proc Soc Exp Biol Med 1998;219:211216.

38 Bogatcheva NV, Zemskova MA, Gorshkov BA, Kim KM, Daglis GA, Poirier C, Verin AD: Ezrin, radixin, and moesin are phosphorylated in response to 2-methoxyestradiol and modulate endothelial hyperpermeability. Am J Respir Cell Mol Biol 2011;45:1185-1194.

-39 Gorshkov BA, Zemskova MA, Verin AD, Bogatcheva NV: Taxol alleviates 2-methoxyestradiol-induced endothelial permeability. Vascul Pharmacol 2012;56:56-63.

40 Cramer T, Yamanishi Y, Clausen BE, Forster I, Pawlinski R, Mackman N, Haase VH, Jaenisch R, Corr M, Nizet V, Firestein GS, Gerber HP, Ferrara N, Johnson RS: HIF-1alpha is essential for myeloid cell-mediated inflammation. Cell 2003;112:645-657.

41 Roman AC, Carvajal-Gonzalez JM, Rico-Leo EM, Fernandez-Salguero PM: Dioxin receptor deficiency impairs angiogenesis by a mechanism involving VEGF-A depletion in the endothelium and transforming growth factor-beta overexpression in the stroma. J Biol Chem 2009;284:25135-25148.

42 Dubey RK, Jackson EK: Cardiovascular protective effects of 17beta-estradiol metabolites. J Appl Physiol (1985) 2001;91:1868-1883. 